\title{
Transformation of the management model of a petrochemical enterprise in the context of industry 4.0 challenges
}

\author{
Alexey Shinkevich, Naira Barsegyan*, Vladimir Petrov, and Tatyana Klimenko \\ Kazan National Research Technological University, Karl Marx st., 68, Kazan, Russia
}

\begin{abstract}
The need to restructure, redesign or develop a management model on a scientific basis at domestic petrochemical enterprises in the context of the challenges of industry 4.0 and the prospects of industry 5.0, the transition to new management standards, the lack of qualified managers determine the importance and relevance of the problem of choosing the optimal organizational structure of enterprise management that contributes to the most effective achievement of goals. When designing and evaluating the effectiveness of organizational management structures, modeling was used using the production function, which takes into account the indicators of the use of human and material capital in the organization of production. The article summarizes the research and development that allows us to assess the current level of development of organizational structures of petrochemical enterprises in domestic and foreign science and practice. It is proposed to calculate the ranges of indicators of the effectiveness of the management system, depending on the type of organizational structure of management. As a hypothesis, it is noted that with organic types of organizational structures, the level of resource saving is higher than with divisional OSU, the level of resource efficiency of which, in turn, is higher than with mechanistic OSU. The scientific results presented in the study are of significant importance in the context of the implementation of projects on strategies for the development of organizational structures of petrochemical enterprises.
\end{abstract}

\section{Introduction}

Petrochemical enterprises require the introduction of improved management methods and advanced production technologies. To increase competitiveness and ensure efficient operation, petrochemical enterprises need to constantly modernize their strategy to meet changing environmental conditions. When changing the strategy, in order to improve the quality of products, minimize costs, and ensure effective management within the enterprise, it is inevitable to change the organizational structure through its modernization or restructuring. The issues of resource saving are reflected in numerous works of Academician of the Russian Academy of Sciences V. P. Meshalkin [1,2]. The practice of studying strategies for the development of petrochemical enterprises, management systems

*Corresponding author: n.v.barsegyan@yandex.ru 
is revealed in the works of Shinkevich A. I., Kudryavtseva S. S., Malysheva T. V., Galimulina F. F. [3-6], the works of Dyrdonova A. N. are devoted to the definition of activities for the organization and implementation of management tools for industrial enterprises [7], from the point of view of the organization of management and problems of restructuring in industry, the works of Shinkevich M. V. are of interest [8].

The need to restructure, redesign or design a management model on a scientific basis at domestic petrochemical enterprises in the context of the challenges of industry 4.0 and the prospects of industry 5.0 determine the importance and relevance of modeling production organization processes that require knowledge in the field of information technology, reengineering of management structures, which provide advantages in managing industrial enterprises in conditions of limited resources.

\section{Materials and Methods}

The methodological basis of the research is based on modern scientific approaches to the design of industrial organization management systems and organizational management structures and optimization of economic resources of the enterprise.

The methodological basis of the study was a set of management methods based on a systematic approach to the study of issues on the subject of the study. In order to identify patterns and analyze the state of problems, we used methods of cause-and-effect relationships, methods of formalization; in assessing the impact of management structure indicators on the organization of production processes, economic and statistical methods were used; in designing and evaluating the effectiveness of organizational management structures, modeling based on the IDEF0 methodology and methods of queuing theory were used.

\section{Results and Discussion}

The head is responsible for the organization of production systems, the use of allocated resources for their development, and the modernization of the technological process at the enterprise, delegating his powers to the responsible persons in the divisions and controlling their activities. The process of performing tasks by structural divisions within the organization of production of the enterprise leads to the emergence of an organizational management structure. In this regard, the optimization of the organizational structure of management is carried out in accordance with the company's strategy in order to effectively organize production processes. The relationship between the company's strategy and its organizational management structure is shown in Figure 1.

When expanding the production of petrochemical products, sales markets, and innovative development, there is a need for changes in the structure, composition, and internal elements of the organization. The rapidly changing situation in the Russian market requires the development of new strategies, which also makes it necessary to change the organizational structure of enterprises. In the modern literature, the following types of organizational management structures are distinguished: mechanistic (linear, functional, linear-functional and linear-staff); divisional and organic (project, program-target, matrix, brigade, multidimensional, network, virtual). Each type of organizational structure has its own advantages and disadvantages, and can be formed in accordance with a specific strategy for the development of the enterprise. 


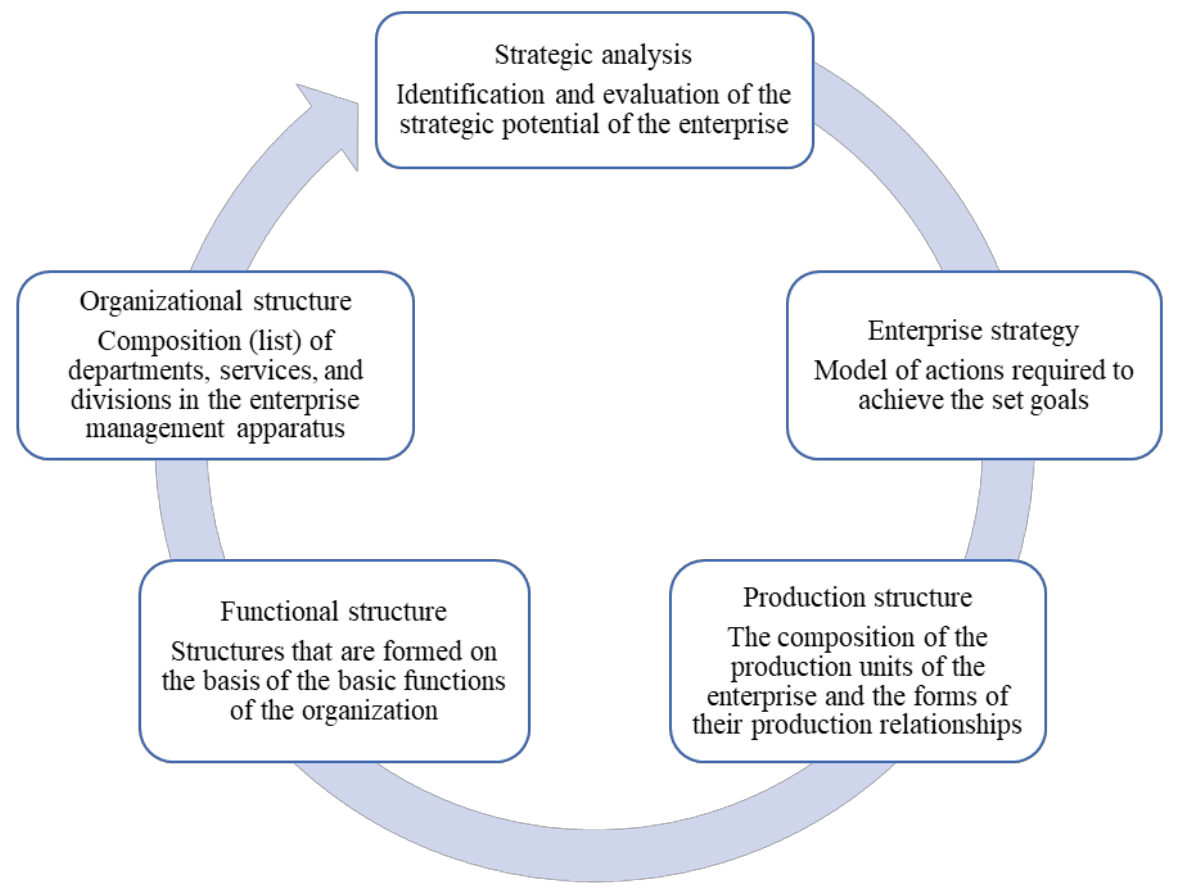

Fig. 1. The relationship of the company's strategy with the organizational structure of management (developed by the author)

The analysis of resource efficiency indicators within petrochemical enterprises belonging to different types of organizational management structures revealed the relationship between the level of resource saving and the type of OSM (Table 1).

Table 1. The relationship between the level of resource efficiency and the type of organizational structure of management (proposed by the author).

\begin{tabular}{|c|c|c|}
\hline $\begin{array}{c}\text { Type of organizational } \\
\text { management } \\
\text { structure }\end{array}$ & \multicolumn{2}{|c|}{ Resource efficiency indicator (Y) } \\
\hline Mechanistic OSM $(\mathrm{Xm})$ & $\begin{array}{c}\mathrm{Y}_{\mathrm{m}}=\mathrm{a}_{\mathrm{m}} * \mathrm{X}_{\mathrm{m}}+\mathrm{b}_{\mathrm{m}} \\
\text { by } \mathrm{X}_{\mathrm{m}} \in\left(\mathrm{m}_{\mathrm{i}} ; \mathrm{m}_{\mathrm{j}}\right)\end{array}$ & $\begin{array}{c}\text { Effective for petrochemical enterprises with } \\
\text { mass production (for example, } \\
\text { Nizhnekamskneftekhim) }\end{array}$ \\
\hline Divisional OSM $(\mathrm{Xd})$ & $\begin{array}{l}\mathrm{Y}_{\mathrm{d}}=\mathrm{a}_{\mathrm{d}} * \mathrm{X}_{\mathrm{d}}+\mathrm{b}_{\mathrm{d}} \\
\text { by } \mathrm{X}_{\mathrm{d}} \in\left(\mathrm{d}_{\mathrm{k}} ; \mathrm{d}_{\mathrm{n}}\right)\end{array}$ & $\begin{array}{c}\text { Effective for enterprises with a mixed type of } \\
\text { production (for example, Kazanorgsintez) }\end{array}$ \\
\hline Organic OSM (Xo) & $\begin{array}{l}\mathrm{Y}_{\mathrm{o}}=\mathrm{a}_{\mathrm{o}} * \mathrm{X}_{\mathrm{o}}+\mathrm{b}_{\mathrm{o}} \\
\text { by } \mathrm{X}_{\mathrm{o}} \in\left(\mathrm{o}_{\mathrm{p}} ; \mathrm{o}_{\mathrm{s}}\right)\end{array}$ & $\begin{array}{c}\text { It is effective for petrochemical enterprises with } \\
\text { a wide-profile production (for example, JSC " } \\
\text { KVART») }\end{array}$ \\
\hline
\end{tabular}

The table $\mathrm{Y}$ - the value of resource efficiency with an index corresponding to the type of organizational structure, $X$ - type organizational structure, characterized by normal handling, a speed ratio change of the influence of $\mathrm{X}$ on $\mathrm{Y}$.

The revealed dependences show that organic organizational structures, the level of resource efficiency higher than at divisional OSU, the level of resource efficiency which, in turn, higher than in mechanistic OSM.

From the point of view of the development of organizational management structures at petrochemical enterprises, we consider it appropriate to conduct modeling using the production function, which takes into account the indicators of the use of human and 
material capital in the organization of production. Taking into account the directions of digitalization, increasing the level of innovation in production and the development of industry 4.0 as a result variable, as an indicator of the effectiveness of the production process, we suggest using such an indicator as " shipment of innovative products to one petrochemical enterprise»; as explanatory variables - the indicator of labor resource utilization, expressed in terms of the share of high-performance jobs in the total number of employees in petrochemical enterprises and the indicator of the use of material capital, as the coefficient of renewal of fixed assets in the petrochemical industry. Our calculations are based on the average values for the petrochemical industry, which includes such subspecies of activity as "chemical production" and "production of rubber and plastic products". The choice of these indicators for modeling was determined by the results of the component and factor analysis, which showed the greatest influence on the design of organizational management structures in the petrochemical industry of such factors as personnel and innovation, technical and technological and material potential of production, which will be taken into account when constructing the production function.

We will use the classical model of the production function proposed by Cobb-Douglas:

$$
\mathrm{y}=\mathrm{A} \times \mathrm{K}^{\alpha} \times \mathrm{L}^{\beta},
$$

where in our case:

$\mathrm{Y}$ - volume of innovative products shipped to one petrochemical enterprise, million rubles;

$\mathrm{K}$ - coefficient of renewal of fixed assets (material component);

$\mathrm{L}$ - the share of high-performance jobs in the total number of employees at petrochemical enterprises, percentage (personnel component);

$\alpha, \beta$-elasticity coefficients of the model;

A is an independent variable of the model.

As a result of the simulation, the following model of the production function was obtained:

$$
\mathrm{Y}=0,75 \times \mathrm{K}^{-1,22} \times \mathrm{L}^{1,08}
$$

This model is statistically reliable, as indicated by the statistical significance of the coefficients of the equation (p-value less than 0.05); the coefficient of determination was $89 \%$; the Fisher criterion also corresponds to the standard-p-value less than 0.05 ; the average model residuals tend to zero, there is no autocorrelation in the model residuals, which is confirmed by the Darbin-Watson criterion, which was 2.1 (with the standard value equal to 2). The analysis of the model residuals and its characteristics are presented in Table 2.

Table 2. Results of modeling the production function of petrochemical enterprises (calculated by the author).

\begin{tabular}{|c|c|c|c|c|c|c|}
\hline \multirow{2}{*}{} & \multicolumn{6}{|l|}{$\begin{array}{l}\text { Regression Summary for Dependent Variable: Y (Spreadsheet1) } \mathrm{R}=0,94277537 ; \\
\mathrm{R}^{2}=0,88882540 ; \text { Adjusted } \mathrm{R}^{2}=0,8570612 ; \mathrm{F}(2,7)=27,982 \mathrm{p}<, 00046 \text { Std.Error of } \\
\text { estimate: } 0,10212\end{array}$} \\
\cline { 2 - 7 } & $\mathrm{b}^{*}$ & Std.Err. & $\mathrm{b}$ & Std.Err. & $\mathrm{t}(7)$ & $\mathrm{p}$-value \\
\hline Intercept & & & $-0,29$ & 1,17 & $-0,25$ & 0,81 \\
\hline $\mathrm{L}$ & 0,75 & 0,13 & 1,08 & 0,19 & 5,73 & 0,00 \\
\hline $\mathrm{K}$ & $-0,41$ & 0,13 & $-1,22$ & 0,39 & $-3,15$ & 0,02 \\
\hline
\end{tabular}

The unstable dynamics of the renewal of fixed assets affected the negative sign for the variable that characterizes the material capital. At the same time, the growth in the share of high-performance jobs reflected an increase in the number of innovative products shipped 
per petrochemical enterprise. Consequently, the human resource management component was crucial in the development of innovative activities in the petrochemical industry. Therefore, when designing organizational management structures at petrochemical enterprises, the programs of these developments should be focused primarily on the goals of innovative development with the dominant factors of labor costs and their productivity.

\section{Conclusions}

1. It is determined that the strategies of enterprises are implemented through organizational management structures, which are one of the tools for improving the efficiency of the management system.

2.The choice of OSU by petrochemical enterprises, whose strategies are aimed at resource conservation and the development of new products, has been clarified.

3. It is proved that one of the key tools for implementing a lean production system at enterprises is the provision of highly qualified personnel, which act as a source of increasing the efficiency of the enterprise. In this regard, the company's human resource management system should ensure the optimization of labor, change of the organizational structure, continuous improvement and development of personnel.

4. Modeling of the strategy for the development of a lean organizational management structure of a petrochemical enterprise was carried out, the results of which show that the most significant factor to be taken into account when developing and implementing lean organizational management structures is the personnel component.

\section{Acknowledgements}

The reported study was funded by RFBR, project number 20-010-00655.

\section{References}

1. V. I. Bobkov, A. S. Fedulov, M. I. Dli, V. P. Meshalkin, E. V. Morgunova, Clean Technologies and Environmental Policy, 20(10) (2018)

2. V. P Meshalkin, Proc. of 1 Europ. Congr. on Chem. Eng., 4 (1997)

3. A. I. Shinkevich, S. S. Kudryavtseva, I. G. Ershova, International Journal of Energy Economics and Policy, 10(3) (2020)

4. A. I. Shinkevich, F. F. Galimulina, Yu. S. Polozhentseva, A. A. Yarlychenko, N.V. Barsegyan, International Journal of Energy Economics and Policy, 11(3) (2021)

5. S. S. Kudryavtseva, F. F. Galimulina, I. A. Zaraychenko, N. V. Barsegyan, Modern Journal of Language Teaching Methods, 8(10) (2018)

6. A. I. Shinkevich, E. S. Shaimieva, T. V. Malysheva, G. I. Gumerova, Academy of Strategic Management Journal, 19(5) (2020)

7. A. N. Dyrdonova, International Journal of Economics and Financial Issues, 6(S1) (2016)

8. M. V. Shinkevich, Yu. V. Vertakova, F. F. Galimulina, International Journal of Energy Economics and Policy, 10(3) (2020) 